\title{
EGU21-6028
}

https://doi.org/10.5194/egusphere-egu21-6028

EGU General Assembly 2021

(c) Author(s) 2021. This work is distributed under

the Creative Commons Attribution 4.0 License.

\section{Geodynamics of the Central Mediterranean (GEOMED) inferred from ambient seismic noise}

\author{
Matthew Agius ${ }^{1}$, Fabrizio Magrini ${ }^{1}$, Giovanni Diaferiaa ${ }^{1,2}$, Fabio Cammarano ${ }^{1}$, Claudio Faccenna ${ }^{1}$, \\ Francesca Funiciello ${ }^{1}$, Emanuel Kästle ${ }^{3}$, and Mark van der Meijde ${ }^{4}$ \\ 1Università Roma Tre:, Dipartimento di Scienze, Rome, Italy (matthew.agius@uniroma3.it) \\ ${ }^{2}$ Istituto Nazionale di Geofisica e Vulcanologia, Rome, Italy. \\ ${ }^{3}$ Institute of Geological Sciences, Freie Universität Berlin, Berlin, Germany. \\ ${ }^{4}$ Faculty of Geo-Information Science and Earth Observation, University of Twente, The Netherlands.
}

The Central Mediterranean, the area encompassing Italy, Sardinia, Tunisia and Libya, is characterised by multiple tectonic processes (plate convergence, subduction, and backarc extension). The evolution and interaction of the plate margins within this relatively small area are still being unravelled particularly at the adjacent region known as the Sicily Channel located between Sicily, Tunisia, Libya and Malta. This Channel is characterised by a seismically and volcanically active rift zone. Much of the observations we have today for the southern parts of the Calabrian arc are either limited to the surface and the upper crust, or are broader and deeper from regional seismic tomography, missing important details about the lithospheric structure and dynamics. The project GEOMED (https://geomed-msca.eu) addresses this issue by processing all the seismic data available in the region in order to understand better the geodynamics of the Central Mediterranean.

We measure Rayleigh- and Love-wave phase velocities from ambient seismic noise recordings to infer the structures of the Central Mediterranean, from the Central Apennines to the African foreland, with a special focus on the Sicily Channel Rift Zone (SCRZ). The phase-velocity dispersion curves have periods ranging from 5 to 100 seconds and sample through the entire lithosphere. We invert the dispersion data for isotropic and polarised shear velocities with depth and infer crustal thickness and patterns of radial anisotropy. We find that continental blocks have thick crust (30-50 $\mathrm{km})$, whereas beneath the SCRZ the crust is thin $(<25 \mathrm{~km})$, and thinner beneath the Tyrrhenian Sea. Beneath the SCRZ and the Tyrrhenian Sea, the crustal shear velocities are characterised by positive radial anisotropy $\left(\mathrm{V}_{S H}>\mathrm{V}_{\mathrm{SV}}\right)$ indicative of horizontal flow or extension, whereas the uppermost mantle is characterised by slow shear velocities indicative of warmer temperatures and strong negative radial anisotropy $\left(\mathrm{V}_{S \mathrm{~S}}>\mathrm{V}_{\mathrm{SV}}\right)$ indicative of vertical flow. We discuss the relevance of these findings together with other geophysical studies such as the regional seismicity and GPS velocity vectors to identify the rifting process type of the SCRZ.

This project has received funding from the European Union's Horizon 2020 research and innovation programme under the Marie Skłodowska-Curie grant agreement No 843696. 